\title{
Factors Influencing Subscribers' Use and Adoption of the NHIS Mobile Renewal Service
}

\author{
Amma Addae-Nketiah \\ College of Public Administration, Huazhong University of Science and Technology, Wuhan, China \\ Email: aaddae10@caledonian.ac.uk, aatsugah@gmail.com
}

How to cite this paper: Addae-Nketiah, A. (2022). Factors Influencing Subscribers' Use and Adoption of the NHIS Mobile Renewal Service. Open Journal of Social Sciences, 10, 451-475.

https://doi.org/10.4236/jss.2022.102032

Received: January 11, 2022

Accepted: February 25, 2022

Published: February 28, 2022

Copyright $\odot 2022$ by author(s) and Scientific Research Publishing Inc. This work is licensed under the Creative Commons Attribution International License (CC BY 4.0).

http://creativecommons.org/licenses/by/4.0/

\begin{abstract}
This paper reports a research work that examined the applicability of the Technology Acceptance Model (TAM) in explaining clients' decisions to accept the Mobile Renewal Service (MRS) technology introduced by the National Health Insurance Scheme in Ghana. The model's overall fit, explanatory power, and the individual causal links that it postulates were evaluated by examining the adoption and usage of the Mobile Renewal Service technology among clients in the Northern Region of Ghana. Results of the study suggested that Technology Acceptance Model (TAM) was able to provide a reasonable depiction of clients' adoption and usage of the Mobile Renewal Service. The study reports $0.762 R^{2}$ (with $\mathrm{T}$ statistics greater than 1.96 and $P$ value less than 0.05 ) indicating that the independent variables, namely System Quality, Transaction Cost, Accessibility, Perceived Ease of Use and Perceived Usefulness, all together explain about 76.2 percent changes in intention to use mobile renewal services. Accessibility and perceived ease of use are both capable of influencing perceived usefulness positively. It can be established that accessibility facilitates subscriber intention to use the mobile renewal service. The study also concludes that system quality is able to influence user's desire to use the service. The findings in this regard suggest that the underlying variables explained the substantial variance in the subscribers' intention to use mobile renewal services of the NHIS.
\end{abstract}

\section{Keywords}

Adoption, National Health Insurance Scheme, Mobile Renewal Service, Technology Acceptance Model

\section{Introduction}

Ghana's public sector is undergoing a period of rapid transformation as far as 
ICT is concerned. Government institutions with established offline services are increasingly leveraging their brand equity to develop online services. The government of Ghana is committed to transforming the public service base with electronic government solutions. Ghana's Ministry of Health has put together some objectives to be achieved under the Government of Ghana's Universal Health Coverage (UHC) plan. Again, as part of the e-Ghana plan modules, government agencies have been tasked to use various ICTs and other E-government solutions.

One of the government agencies spearheading the surge forward into the information age is the National Health Insurance Authority (NHIA) with the Mobile Renewal Service's introduction, enabling subscribers of the National Health Insurance Scheme (NHIS) to renew their expired NHIS cards with their mobile phones. The service provides many advantages over the traditional service renewal like the everywhere/anytime service availability, elimination of queues, and reduced branch working hours. Despite its many advantages, adopting technology has its drawbacks. Using technological applications requires users to abandon their old habits. This can lead to an aversion to new technology (Sakala \& Phiri, 2019).

\subsection{Background to the Study}

The National Health Insurance Scheme (NHIS) launched the Mobile Renewal Service on 17 December 2018 to renew its membership without hassle. This creative method of renewal of membership and premium payment aims to increase the enrollment and retention rates of Ghana's NHIS. The service can be accessed by dialing ${ }^{*} 929$ \# from any mobile phone network.

Although the mobile renewal service's introduction seems to have eased congestion at the various NHIS District offices nationwide, saved time, and lowered operational costs, there are no empirical studies to test how citizens have accepted this service and are using it. Considering how efficient and effective the mobile renewal service is, it is worthwhile to investigate the factors influencing subscribers' use and adoption of the service and how NHIA can improve upon the service to cover a broader range.

\subsection{Literature Review}

This chapter presents the review-related literature underpinning the study. It covers the conceptual review, as well as the review of concepts relevant to the course of this study. The study focuses on the notion of e-service, which is a practical use of information and communication technology in various areas. The World Health Organization (WHO) defines e-health as "cost-effective and secure use of ICTs for health and related fields". Ghana can become one of the first countries in the world to build a robust, state-of-the-art health ICT platform and generate unique ID numbers for all patients. There are about 22 eHealth projects at various stages of completion in Ghana (Afarikumah, 
2014). In 2005, Robert Istephanie coined the word mHealth to denote the "emerging healthcare mobile communications and network technologies". World Health Organization defines mHealth as a medical practice supported by mobile devices. Researchers have begun investigating mHealth's potential such as mobile interventions' effectiveness in people with HIV. Research on the adoption of mobile services is still in its infancy. It's critical to assess the current state of the Mobile Renewal Service as well as its acceptability. Mobile money allows users to store, send, and receive money using their mobile phones. There are more than 270 different mobile money services available around the world. Mobile money has become a popular alternative to bank accounts because it is safe and simple to use. It can be used on both smartphones and basic feature phones. The National Health Insurance Scheme (NHIS) covers only around half of Ghana's population of about 30 million people. The plan does not cover HIV/AIDS treatment, vaccination, or family planning services. It is necessary to renew the NHIS card every year if you want to keep it for another five years.

\subsubsection{Factors Influencing Subscriber Use and Adoption of a New Health System}

Kim, Lee, Hwang, and Yoo (2016) study the factors that impact users' intentions to utilize a mobile electronic health records (EMR) system using a questionnaire survey and a log file analysis. According to the findings, Performance Expectancy on Attitude and Attitude impact intention to utilize the system. According to the research, TAM predicts a substantial share of the desire to install clinical information systems. The findings contribute to the literature by reproducing, explaining, and expanding the TAM, while the addition of external factors and a moderator strengthens the theory. To ensure the effective implementation of new health technologies, Safi, Thiessen, and Schmailzl (2018) seek to determine and assess the factors that influence acceptance and resistance. Patients in Brandenburg as well as major players in the local healthcare system are included in the target group. Basak, Gumussoy, and Calisir (2015a) investigate the factors influencing physicians' intentions to use PDA technology. Perceived usefulness and perceived ease of use account for 71 percent of physicians' intention to employ PDA tech. The information was gathered from 339 doctors in Turkey. Ifinedo (2015) evaluated the moderating effects of demographic (i.e., educational level and age) and individual characteristics on nurses' implementation of information systems (IS). The number of years of nursing experience and the age of the nurses did not affect the outcomes. The literature stated ab.

\subsubsection{Technology Acceptance Model}

The Technology Acceptance Model (TAM) is one of the most often discussed technological usage hypotheses. Davis (1989) established this theoretical model to foresee and define ICT use activities. TAM implies that people would accept 
and use technology if they believe it will be beneficial and simple to use. As a result, the more people agree that a system may make their activities simpler to complete, the more likely they are to adopt it and accept new technology as valuable (Dillon \& Morris, 1996). TAM was first proposed by Davis and is based on the Theory of Reasoned Action (TRA) (Ajzen \& Fishbein, 1980). According to the TRA, social conduct is influenced by an individual's attitude toward information systems (Lin, 2007).

In TAM, two theoretical variables, Perceived Usefulness (PU) and Perceived Ease of Usage (PEOU) are important drivers of system use and predict attitudes toward utilizing the system, i.e. the user's desire to use the technology. Perceived usefulness refers to "the degree to which a person believes that using a particular system would enhance his or her job performance," and perceived ease of use refers to "the degree to which a person believes that using a particular system would be free of effort" (Davis, 1989). Furthermore, $\mathrm{PU}$ and PEOU may be influenced by a variety of external circumstances. External factors may include student characteristics, system features, and the environment in which the system is utilized (Wojciechowski \& Cellary, 2013). Fishbein and Ajzen (1975), and Davis and Cosenza (1993) describe behavioral intention (BI) as the objectives, ambitions, and anticipated reactions to the attitude object.

Although TAM is widely used to measure the degree of acceptance of technology by users due to its simple and easy-to-understand nature, Luke, Mwolo, \& Omwansa (2012) contend that TAM is not suitable for or practice applicable to firms, companies, or organizations.

Despite its limitations, the TAM model has aided educators, practitioners, and academics in the acceptance and use of technology. TAM has been applied to various technologies such as word processors, email, WWW, GSS, and hospital information systems. It has effectively forecasted IS adoption behavior under a variety of technologies and contexts (Mohammed-Issa, 2013).

\subsection{Purpose of Study}

The study seeks to investigate the adoption of the mobile renewal service under the National Health Insurance Scheme (NHIS) in Ghana. Precisely, the study seeks to:

1) Assess the status quo and the degree of subscriber acceptance of the service, i.e., to determine this service's perception and the level of recognition in society by service providers and subscribers.

2) Identify what influences the subscribers' use and adoption or otherwise of the Mobile Renewal Service.

\section{Methodology and Conceptual Framework}

\subsection{Conceptual Framework Development and Hypothesis}

This study employs the Technology Acceptance (TAM) model to investigate the 
individual acceptance of and intention to use the Mobile Service Renewal with external variables which are; System quality, Transaction Cost, and Accessibility in addition to the Perceived Usefulness; Perceived Ease of Use and Intention to Use (Figure 1 and Figure 2).

\section{Hypotheses underlying the Study}

The study has predicted a host of hypotheses about what influences the subscribers' adoption and intention to use or otherwise of the Mobile Renewal Service.

\section{System Quality}

The notion of how effectively a system accomplishes activities that are aligned with work objectives is referred to as system quality (Davis \& Venkatesh, 2000). It is expected that the study will show that System Quality will have some effect on subscriber Intention to Use the Mobile Renewal Service. The estimation of the performance characteristics of the system under investigation is generally the focus of measurement.

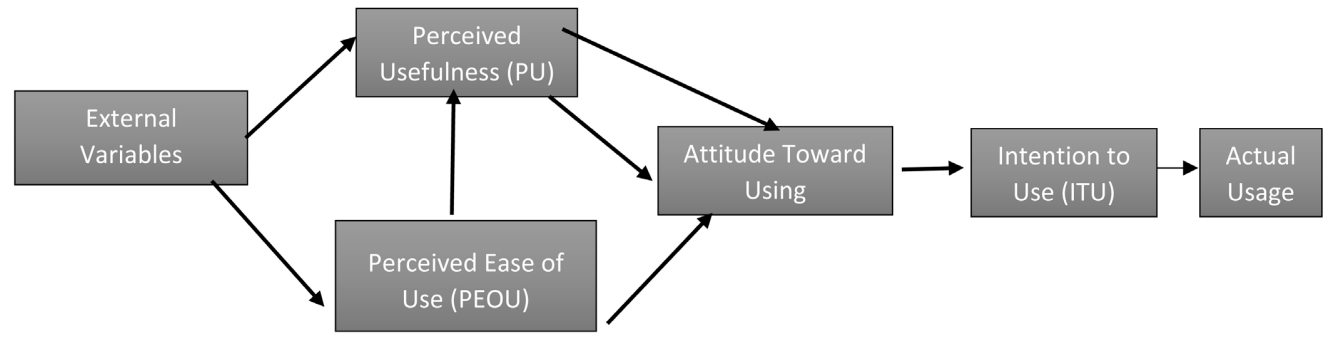

Figure 1. The technology acceptance model. Source: Davis et al., 1989.

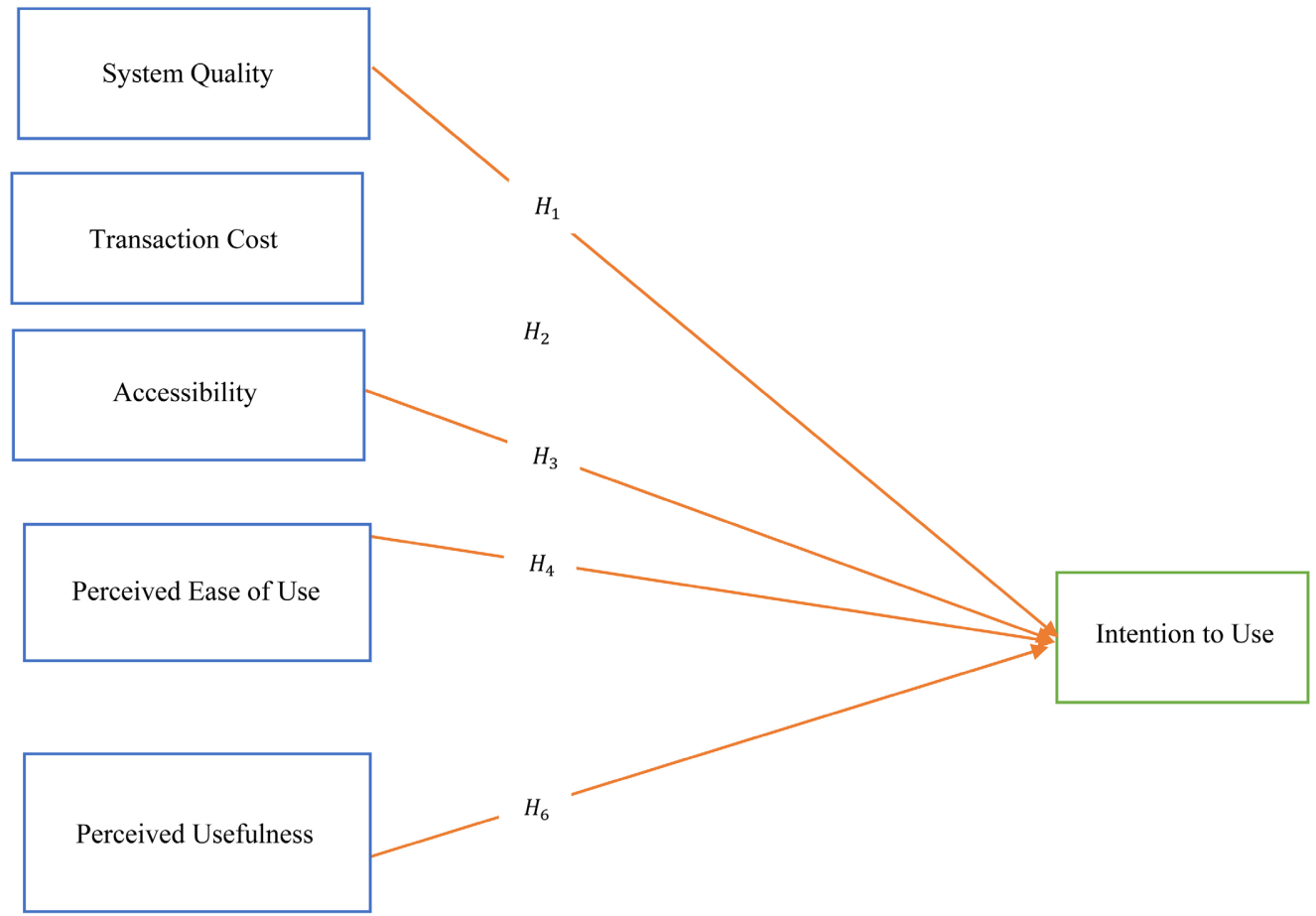

Figure 2. The adopted conceptual framework. Source: Author's construct. 
$H_{1}$ : System Quality will have a positive effect on subscriber Intention to Use the Mobile Renewal Service.

\section{Transaction Cost}

Many customers may be put off by the cost of using the mobile renewal service. Consumers are more inclined to embrace and utilize a service if they believe the transaction cost is reasonable. This variable was previously utilized in M-banking adoption studies (Luarn \& Lin, 2004).

$\mathrm{H}_{2}$ : Transaction Cost will have a negative effect on subscriber Intention to Use the Mobile Renewal Service.

\section{Accessibility}

Mobile Renewal Service's physical and information accessibility can have a substantial impact on users' Intention to Use. Accessibility refers to a person's ability to physically access the hardware required to operate the system. The easier a system is to interact with, the less effort is required to use it (Davis, 1989).

$H_{3}$ : Accessibility will have a positive effect on subscriber Intention to Use the Mobile Renewal Service.

\section{Perceived Ease of Use, Perceived Usefulness, and Intention to Use}

Perceived utility and perceived ease of use are both opinions. As a result, they will have an impact on the user's intents. Perceived Ease of Use and Perceived Usefulness will also have some effect on subscriber Intention to Use the Mobile Renewal Service.

$H_{4}:$ Perceived Ease of Use will have a positive effect on subscriber Intention to Use the Mobile Renewal Service.

$H_{5}$ : Perceived Usefulness will have a positive effect on subscriber Intention to Use the Mobile Renewal Service.

\subsection{Research Design, Population, Sample Size Determination and Data Processing Procedure}

The study used a descriptive-correlational survey design. The study used the descriptive type to evaluate the status quo and degree of subscriber acceptance of the service, i.e., to determine the service's perception and level of recognition in society by subscribers, as well as the benefits and challenges associated with its use, and the explanatory type (correlational) to ascertain what influences subscribers' intentions to use or not use the Mobile Renewal Service.

This study adopted the quantitative approach. The quantitative research approach enables the collecting of quantitative data into hypotheses. Quantitative research is the best technique for studying huge data sets since it is inexpensive and time-efficient probability sampling techniques and offers results that may be applied to the research population (Bhattacherjee, 2001; Kumar, 2011). The population considered in this study is subscribers selected from 11 out of the 13 District Offices of the NHIS in the Northern Region. A sample of about 50 subscribers purposively selected from the population from each District Office was randomly selected. These constituted a fair representation of the organization 
being studied and whose perception and orientation affects the adoption of and intention to use the Mobile Renewal Service.

The study utilized a survey questionnaire in the collection of the quantitative data for the study.

Having gathered the relevant data from the participants, the investigator entered, processed, and analyzed them using the IBM Statistical Package for Social Sciences (SPSS) Version 21 software application, Smart PLS and Microsoft Excel Package. The analysis was done using both descriptive and inferential statistical analysis tables, graphs, and charts. The descriptive statistics of frequency distributions and means scores-standard deviation techniques were used for the demographic profile of the participants as well as status quo and degree of subscriber acceptance and intention to use of the service.

Cluster of District in the Northern Region

\begin{tabular}{cccc}
\hline No. & Districts & Capital & Sampled Subscribers \\
\hline 1 & Tamale Metropolitan & Tamale & 52 \\
2 & Sagnarigu & Sagnarigu & 47 \\
3 & Savelugu & Savelugu & 47 \\
4 & Gushegu & Gushegu & 46 \\
5 & Karaga & Karaga & 45 \\
6 & Saboba & Kpandai & 43 \\
7 & Tolon Kumbugu & Kumbugu & 45 \\
8 & Zabzugu & Sang & 42 \\
9 & Nanumba South & Yendi & 48 \\
10 & Nanton & Nanton & 45 \\
11 & Nanumba North & Bimbilla & 40 \\
& Total & & 500
\end{tabular}

Source: (Ghana Statistical Service, 2015).

\section{Analysis and Discussion}

\section{Demographic Profile of Respondents}

This section presents the analysis of respondents' background information as part of the exploration of the adoption of the mobile renewal services under the NHIS.

Table 1 presents findings on the demographic characteristics of the participants of the study. Concerning gender, the study reports 224 (55.31\%) and 181 $(44.69 \%)$ respectively for males and females. The finding implies that male participants dominate the study. About the age group distribution, it reports 197 (48.64\%) and 144 (35.56\%) for 21 - 29 and 30 - 39 age groups, respectively, with 50 years plus as least participating age group (2.72\%). The result posits youngsters as the main participants in the study. The education attainment 
Table 1. Reliability test outcome for constructs under investigation.

\begin{tabular}{|c|c|c|c|}
\hline \multirow{2}{*}{\multicolumn{2}{|c|}{ Characteristics }} & \multicolumn{2}{|c|}{ Frequency } \\
\hline & & $\mathrm{N}=94$ & Percent \\
\hline \multirow{2}{*}{ Gender } & Male & 224.00 & 55.31 \\
\hline & Female & 181.00 & 44.69 \\
\hline \multirow{4}{*}{ Age } & $21-29$ years & 197.00 & 48.64 \\
\hline & $30-39$ years & 144.00 & 35.56 \\
\hline & $40-49$ years & 53.00 & 13.09 \\
\hline & 50 years and above & 11.00 & 2.72 \\
\hline \multirow{6}{*}{ Education Attainment } & High School or below & 44.00 & 10.86 \\
\hline & Diploma & 134.00 & 33.09 \\
\hline & Bachelor & 118.00 & 29.14 \\
\hline & Masters & 50.00 & 12.35 \\
\hline & $\mathrm{PhD}$ & 2.00 & 0.49 \\
\hline & Professional Certificate & 57.00 & 14.07 \\
\hline \multirow{3}{*}{ Employment } & Private Sector & 44.00 & 10.86 \\
\hline & Public Sector & 194.00 & 47.90 \\
\hline & Unemployed & 167.00 & 41.23 \\
\hline
\end{tabular}

Source: Author's construct.

distribution of the respondents' records 134 (33.09\%) and 118 (29.14\%), respectively, for Diploma and Bachelor. The other educational qualification distributions include $50(12.35 \%)$ and Two (0.49\%), respectively, for Masters Ph.D. holders. The finding indicates that most of the participants possess considerable education qualifications, making them the most appropriate subscribers to participate in the study. Finally, the employment status distribution report includes 194 (47.90\%) and 167 (41.23\%), respectively for Public Sector and Unemployed, with Private Sector employees having the least representation. The results posit the Public Sector works as the most represented group in the study.

\section{Descriptive Statistics}

The study used 19 items in the preparation of the questionnaire. Items were evaluated for their standard deviations, mean scores, skewness, and kurtosis. Table 2 presents descriptive statistics for the measurement items. The study reports mean scores greater than 2.50 mid-point threshold in the literature.

\section{Assessing Factors Influencing Subscribers' Use and Adoption of the Mobile Renewal Service}

This section presents findings in response to the research question: What factors 
Table 2. Descriptive statistics of measurement items.

\begin{tabular}{|c|c|c|c|c|c|c|c|}
\hline & $\mathrm{N}$ & Minimum & Maximum & Mean & $\begin{array}{c}\text { Std. } \\
\text { Deviation }\end{array}$ & Skewness & Kurtosis \\
\hline \multicolumn{8}{|l|}{ Perceived } \\
\hline \multicolumn{8}{|c|}{ Usefulness } \\
\hline PU1 & 405 & 1.00 & 5.00 & 1.85 & 1.30 & 1.40 & 0.62 \\
\hline PU2 & 405 & 1.00 & 5.00 & 1.81 & 1.25 & 1.48 & 1.03 \\
\hline PU3 & 405 & 1.00 & 5.00 & 2.01 & 1.22 & 1.11 & 0.23 \\
\hline PU4 & 405 & 1.00 & 5.00 & 2.52 & 1.25 & 0.51 & -0.72 \\
\hline \multicolumn{8}{|l|}{ Perceived } \\
\hline \multicolumn{8}{|c|}{ Ease of Use } \\
\hline PEOU1 & 405 & 1.00 & 5.00 & 2.00 & 1.27 & 1.09 & 0.03 \\
\hline PEOU2 & 405 & 1.00 & 5.00 & 2.08 & 1.24 & 1.01 & -0.02 \\
\hline PEOU3 & 405 & 1.00 & 5.00 & 3.21 & 1.29 & -0.24 & -1.01 \\
\hline PEOU4 & 405 & 1.00 & 5.00 & 2.10 & 1.16 & 1.06 & 0.40 \\
\hline \multicolumn{8}{|l|}{$\begin{array}{l}\text { Intention } \\
\text { to Use }\end{array}$} \\
\hline IU1 & 405 & 1.00 & 5.00 & 1.81 & 1.23 & 1.49 & 1.10 \\
\hline IU2 & 405 & 1.00 & 5.00 & 2.05 & 1.18 & 1.06 & 0.28 \\
\hline IU3 & 405 & 1.00 & 5.00 & 1.83 & 1.25 & 1.49 & 1.04 \\
\hline $\begin{array}{l}\text { System } \\
\text { Quality }\end{array}$ & \multicolumn{6}{|c|}{ System } & \\
\hline SQ1 & 405 & 1.00 & 5.00 & 2.10 & 1.16 & 1.00 & 0.23 \\
\hline SQ2 & 405 & 1.00 & 5.00 & 1.96 & 1.11 & 1.14 & 0.59 \\
\hline \multicolumn{8}{|c|}{ Transaction } \\
\hline \multicolumn{8}{|l|}{ Cost } \\
\hline $\mathrm{TC} 1$ & 405 & 1.00 & 5.00 & 3.53 & 1.33 & -0.55 & -0.85 \\
\hline TC2 & 405 & 1.00 & 5.00 & 3.43 & 1.33 & -0.51 & -0.89 \\
\hline TC3 & 391 & 1.00 & 5.00 & 3.38 & 1.32 & -0.46 & -0.92 \\
\hline \multicolumn{8}{|c|}{ Accessibility } \\
\hline $\mathrm{AC} 1$ & 405 & 1.00 & 5.00 & 2.40 & 1.19 & 0.51 & -0.63 \\
\hline $\mathrm{AC} 2$ & 405 & 1.00 & 5.00 & 3.16 & 1.21 & -0.22 & -0.85 \\
\hline $\mathrm{AC} 3$ & 405 & 1.00 & 5.00 & 2.28 & 1.35 & 0.69 & -0.74 \\
\hline
\end{tabular}

Source: Author's construct.

influence the Mobile Renewal Service's adoption and usage among subscribers? The study adopted the PLS-SEM in the testing the five hypotheses $\left(H_{1}, H_{2}, H_{3}\right.$, $H_{4}, H_{5}$ ) proposed in the study. Accordingly, the study developed two main models namely the measurement model and structural model. The PLS-SEM tech- 
nique involves creating a measurement model that shows the validity and reliability of measures and constructs, as well as a structural model that shows the predictive power of endogenous constructs (independent variable) using $R$ square measures and effect size (f square), which determine whether a predictor variable has a significant impact on the dependent variable. The path coefficient, which reflects the conceptual relationship between the latent variables and the models' predictive relevance as assessed by $\mathrm{Q}$ square, is also estimated using the structural model. PLS-SEM, like most analytical techniques, offers rules of thumb for evaluating model findings (Chin, 1998, 2010; Gotz, Liehr-Gobbers, \& Krafft, 2010; Hair, Hult, Ringle, Sarstedt, \& Thiele, 2017a; Henseler, Ringle, \& Sinkovics, 2009; Roldán \& Sánchez-Franco, 2012; Tenenhaus, Esposito Vinzi, Chatelin, \& Lauro, 2005). By their very essence, rules of thumb are broad guides that advise how to interpret the results, and they usually change depending on the circumstances. The final step in interpreting PLS-SEM data is to execute a robustness check to ensure that the results are stable.

\section{Assessing the Measurement Model}

Following the preparation of the data collected from the field survey, it became necessary to commence the actual data analysis which started with the assessment of the demographic profile of the participant and now the development and evaluation of the measurement model. The measurement model covers assessment for indicator reliability (loadings), construct reliability (composite reliability), convergent validity (average variance extracted (AVE) analysis), and discriminant validity (Fornell-Larker criterion a cross-loadings analysis) using generally accepted decision criteria. These validity and reliability tests will provide some assurance that the measurement items used in the questionnaire are assessing the constructs that are supposed to be investigated (Hair, Risher, Sarstedt, \& Ringle, 2019; Sarstedt, Ringle, \& Hair, 2017). The various reliability and validity tests carried out in this assessment are presented in the following sub-sections:

\section{Tests for Reliability}

This sub-section presents both indicator reliability and construct reliability tests using composite reliability and Cronbach alpha, respectively, for the assessment of the internal consistency of each of the constructs. It also presents the indicator loading of the items use in the determination of reliability of measurements. Table 3 reports the reliability tests outcome for the measurement model. All the constructs recorded Cronbach alpha scores more than the 0.70 thresholds in Chin \& Marcoulides (1998) except for Accessibility (0.416) and Perceived Ease of Use (0.663). In the case of composite reliability, all constructed recorded scores greater than the 0.7 benchmarks recommended in George (2003), except for Accessibility (0.668). Reporting greater Cronbach alpha and composite reliability scores for most of the constructions suggest adequate internal consistency as reported in the extant literature (Chin, 1998, 2010; Hair et al., 2017; Hair et al., 2019; Sarstedt et al., 2017). However, the poor performance 
Table 3. Reliability tests outcome for the measurement model (All items included).

\begin{tabular}{|c|c|c|c|c|}
\hline Constructs \& Items & $\begin{array}{c}\text { Factor } \\
\text { Loadings }\end{array}$ & $\begin{array}{c}\text { Cronbach } \\
\text { Alpha }\end{array}$ & $\begin{array}{l}\text { Composite } \\
\text { Reliability }\end{array}$ & AVE \\
\hline \multicolumn{2}{|c|}{ Accessibility } & 0.416 & 0.668 & 0.543 \\
\hline $\mathrm{AC} 1$ & 0.911 & & & \\
\hline $\mathrm{AC} 2$ & -0.133 & & & \\
\hline AC3 & 0.884 & & & \\
\hline \multicolumn{2}{|c|}{ Intention to use } & 0.894 & 0.934 & 0.826 \\
\hline IU1 & 0.941 & & & \\
\hline IU2 & 0.867 & & & \\
\hline IU3 & 0.917 & & & \\
\hline \multicolumn{2}{|c|}{ Perceived Ease of Use } & 0.663 & 0.816 & 0.617 \\
\hline PEOU1 & 0.923 & & & \\
\hline PEOU2 & 0.894 & & & \\
\hline PEOU3 & -0.103 & & & \\
\hline PEOU4 & 0.897 & & & \\
\hline \multicolumn{2}{|c|}{ Perceived Usefulness } & 0.880 & 0.919 & 0.743 \\
\hline PU1 & 0.916 & & & \\
\hline PU2 & 0.929 & & & \\
\hline PU3 & 0.907 & & & \\
\hline PU4 & 0.670 & & & \\
\hline \multicolumn{2}{|c|}{ System Quality } & 0.816 & 0.915 & 0.844 \\
\hline SQ1 & 0.928 & & & \\
\hline SQ2 & 0.909 & & & \\
\hline \multicolumn{2}{|c|}{ Transactional Cost } & 0.811 & 0.885 & 0.720 \\
\hline TC1 & 0.875 & & & \\
\hline TC2 & 0.804 & & & \\
\hline TC3 & 0.865 & & & \\
\hline
\end{tabular}

Source: Author's construct.

of Accessibility and Perceived Ease of Use calls for further scrutiny to come out with specific suspicious measurement items. This brings to fourth the need to explore items' factor loadings.

Table 4 also presents the indicator loadings for all the items under investigation. It reports higher loadings for all the items except AC2 (-0.133), PEOU3 (-0.103), and PU4 (0.670) under Accessibility, Perceived Ease of Use, and Perceived Usefulness, respectively, all above the 0.707 thresholds in practice. Items 
Table 4. Reliability tests outcome for the measurement model (Poor items eliminated).

\begin{tabular}{|c|c|c|c|c|}
\hline Constructs \& Items & $\begin{array}{c}\text { Factor } \\
\text { Loadings }\end{array}$ & $\begin{array}{c}\text { Cronbach } \\
\text { Alpha }\end{array}$ & $\begin{array}{l}\text { Composite } \\
\text { Reliability }\end{array}$ & AVE \\
\hline \multicolumn{2}{|c|}{ Accessibility } & 0.772 & 0.897 & 0.814 \\
\hline $\mathrm{AC} 1$ & 0.915 & & & \\
\hline AC3 & 0.890 & & & \\
\hline \multicolumn{2}{|c|}{ Intention to Use } & 0.894 & 0.934 & 0.826 \\
\hline IU1 & 0.941 & & & \\
\hline IU2 & 0.867 & & & \\
\hline IU3 & 0.917 & & & \\
\hline \multicolumn{2}{|c|}{ Perceived Ease of Use } & 0.89 & 0.932 & 0.819 \\
\hline PEOU1 & 0.924 & & & \\
\hline PEOU2 & 0.895 & & & \\
\hline PEOU4 & 0.896 & & & \\
\hline \multicolumn{2}{|c|}{ Perceived Usefulness } & 0.924 & 0.952 & 0.869 \\
\hline PU1 & 0.937 & & & \\
\hline PU2 & 0.937 & & & \\
\hline PU3 & 0.922 & & & \\
\hline \multicolumn{2}{|c|}{ System Quality } & 0.816 & 0.915 & 0.844 \\
\hline SQ1 & 0.928 & & & \\
\hline SQ2 & 0.909 & & & \\
\hline \multicolumn{2}{|c|}{ Transaction Cost } & 0.811 & 0.885 & 0.720 \\
\hline TC1 & 0.875 & & & \\
\hline TC2 & 0.804 & & & \\
\hline TC3 & 0.865 & & & \\
\hline
\end{tabular}

Source: Author's construct.

of loadings of 0.707 or above show that their constructs have more shared variation than error variance (Barroso, Carrion, \& Roldan, 2010; Gotz et al., 2010; Hulland, 1999). The poor performance of AC2, PEOU, and PU and call for their elimination to enhance the internal consistency of the constructs as applied in the extant literature (Hair et al., 2019; Hulland, 1999).

The statistical evidence given in Table 4 using the estimates of the PLS Algorithm approach, which has been applied similarly in several other investigations (Chin, 1998a, Hair et al., 2019), made the elimination of the questionable measurement items imperative. Following the deletion of the suspected measurement items, the study ran another PLS algorithm, which yielded promising loadings for all of the indicators, greater Cronbach alpha scores, and higher 
composite reliability values (see Table 4 ). The study proceeded on to the validity tests after meeting the reliability requirements.

\section{Tests for Validity}

This sub-section presents various validity tests carried out in the study. Instrument validity is assessed using convergent validity and discriminant validity. Convergent validity measures how well items from the same construct reflect the associated factor, whereas discriminant validity measures how dissimilar conceptually comparable concepts are (Hair et al., 2006). The study applied AVE scores for the convergent validity and the Fornell-Larcker criterion and the cross-loadings for the discriminant validity.

Concerning convergent validity, both Table 3 and Table 4 present greater AVE scores greater than the 0.50 acceptable threshold. The adequate validity of the underlying constructs suggests how best the measurement items relate to the constructs. The reception of the convergent validity of the constructs with AVE scores greater than the 0.50 acceptable threshold is consistent with practice.

Table 5 presents the Fornell-Larcker criterion outcome adopted as the first test for discriminant validity. The main criteria are that the square root of AVE that emerges in diagonal cells for each latent variable should be larger than its correlation with any other latent variable (Fornell \& Larcker, 1981). The findings from the second PLS algorithm after the elimination of items with poor loadings indicate that the diagonal elements or values are sizably larger than the off-diagonal components in the corresponding rows and columns, implying an assured validity for further analysis.

The study in addition to the Fornell-Larcker Criterion employed the cross-loadings technique as the second test for determining discriminant validity. Here, the loadings of each measure must be greater on its theoretically assigned construct than on any other construct, and each construct must load the most with its measures to cross-validate items. A large number of researches back this up (Barclay et al., 1995; Schwarz, 2007; Chin, 1998b; Urbach \& Ahlemann, 2010). After that, the cross-loadings were generated by using the PLS

Table 5. Fornell-Larcker criterion.

\begin{tabular}{|c|c|c|c|c|c|c|c|c|}
\hline & Accessibility & $\begin{array}{l}\text { Intention } \\
\text { to Use }\end{array}$ & $\begin{array}{c}\text { Perceived } \\
\text { Ease of Use }\end{array}$ & $\begin{array}{l}\text { Perceived } \\
\text { Usefulness }\end{array}$ & Satisfaction & $\begin{array}{l}\text { System } \\
\text { Quality }\end{array}$ & $\begin{array}{c}\text { Transactional } \\
\text { Cost }\end{array}$ & Trust \\
\hline Accessibility & 0.902 & & & & & & & \\
\hline Intention to Use & 0.575 & 0.909 & & & & & & \\
\hline Perceived Ease of Use & 0.552 & 0.798 & 0.905 & & & & & \\
\hline Perceived Usefulness & 0.436 & 0.769 & 0.813 & 0.932 & & & & \\
\hline System Quality & 0.577 & 0.814 & 0.757 & 0.737 & 0.023 & 0.919 & & \\
\hline Transactional Cost & 0.013 & -0.175 & -0.172 & -0.204 & 0.011 & -0.153 & 0.849 & \\
\hline
\end{tabular}

Source: Author's construct. 
algorithm technique to link the scores of each construct with all of the other measures. Each column was examined to see if each construct loaded the most with its items or if it also loaded the most with measurements from other constructions to determine the loadings. This was done to ensure that all constructs had a bigger variance with their own measures than with other constructions' measures. With the ExceptPEOU3 for Accessibility and PEOU3, respectively, it was revealed during the first PLS algorithm programming that all constructs loaded highest in the measures or indicators assigned to them. During the final PLS algorithm programming, it was observed that all constructs loaded highest in the measurements or indicators assigned to them for all the constructs theoretically designated.

\section{The Verdict of the Measurement Model}

Considered collectively, the outcome of the measurement model indicators presented above suggests resilient final measures used in this investigation. The construct measures are reliable and valid statistically. The measurement models are therefore appropriate for further investigation. The structural model assessment findings are presented in the next section.

\section{Assessing the Structural Model}

This presents the findings emanating from the structural model evaluation. Following the discovery of quality reliability and validity outcome from the measurement model evaluation, the structural model was evaluated to offer evidence for the theoretical model proposed in this work. The structural model displays the ties between constructs that are hypothesized $\left(H_{1}, H_{2}, H_{3}, H_{4}, H_{5}\right)$ in the study's conceptual model. The extracted variance, path coefficients, prediction accuracy, and goodness of fit of the structural model were determined using the bootstrapping resampling approach. This technique ensures that the estimations' stability is checked. For the endogenous variables, the blindfolding procedure was also used to determine the predictive accuracy of the model with 7 omission distances.

The Smart PLS was used to run the bootstrapping re-sampling procedure for each sample group, with 1000 sub-samples, yielding scores depicting the strength of the extracted variance, path coefficients, prediction accuracy, and goodness of fit index, as well as the t-statistics used to assess the significance levels of the forecasts. Figure 3 demonstrates the refined output that eliminated the suspicious measurement items (AC2, PEOU3, PU4 \& TT4) detected during the validity and reliability tests (using the PLS algorithm technique), which was also generated by the bootstrap resampling technique.

\section{Variance Extracted}

This sub-section presents the model's extracted variance, which often refers to the coefficient determination $\left(R^{2}\right)$. The structural model's total effect size is measured by the $R^{2}$. It is the amount of variance explained by the independent variables in the structural model (Barclay et al., 1995; Hair et al., 2006). Chin (1998) proposes the following $R^{2}$ cutoffs: $0.67,0.33$, and 0.19 , respectively for substantial, moderate, and weak, effects. Table 6 reports the $R^{2}$ scores for the 


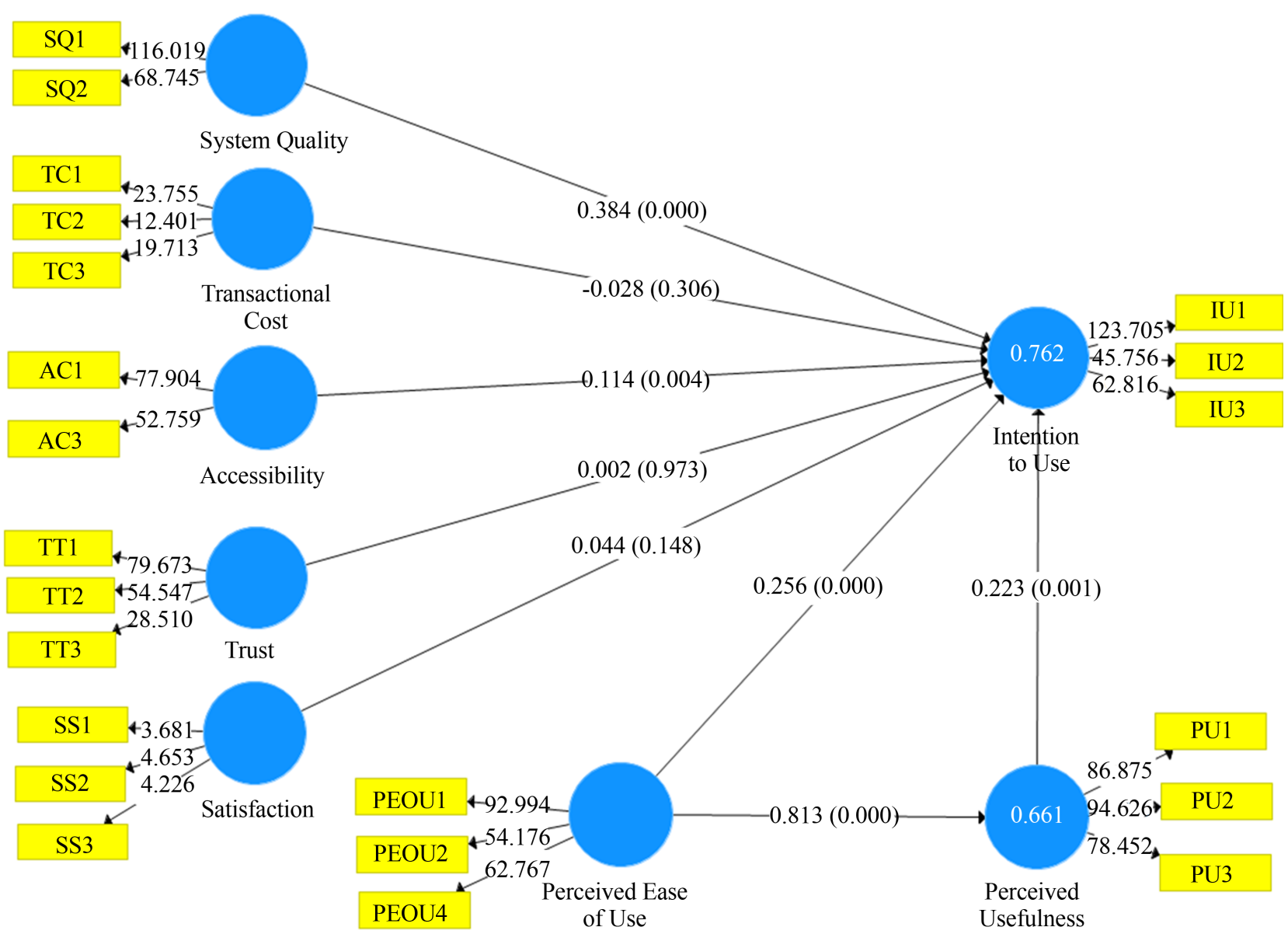

Figure 3. The structural model. Source: Author's construct.

Table 6. Extracted variance $\left(R^{2}\right)$ for the structural model.

\begin{tabular}{cccc}
\hline Constructs & $R^{2}$ & T Values & $P$ Values \\
\hline Intention to Use & 0.762 & 27.805 & 0.000 \\
Perceived Usefulness & 0.661 & 14.010 & 0.000 \\
\hline
\end{tabular}

Note: Significance levels: $\mathrm{n} / \mathrm{s}=$ not significant; ${ }^{\star} 0.05,{ }^{* *} 0.01,{ }^{* *} 0.001$. Source: Author's construct.

structural model. The study report $0.762 R^{2}$ (with $\mathrm{T}$ statistics greater than 1.96 and $P$ value less than 0.05 ) indicating that the independent variables, namely System Quality, Transaction Cost, Accessibility, Perceived Ease of Use and Perceived Usefulness, all together explain about 76.2 percent changes in Intention to Use Mobile Renewal Services. The findings in this regard suggest that the underlying variables explained the substantial variance in the subscribers' Intention to Use Mobile Renewal Services of the NHIS.

\section{Path Coefficients for the Direct Effect Analysis}

This sub-section presents the path analysis for the direct effect of the independent variables on the Intention to Use Mobile Renewal Services of the NHIS. It also entails the hypothesis testing conducted for either acceptance or rejection 
of the defined hypotheses, that is $H_{3}, H_{5}, H_{1}, H_{2}, H_{4}$, respectively explaining the relationship between the following: Accessibility and Intention to Use, Perceived Ease of Use and Intention to Use, Perceived Usefulness and Intention to Use, System Quality and Intention to Use, Transactional Cost and Intention to Use, (see Table 8). The rule of thumb for the PLS-SEM path coefficient analysis suggested in the literature is that $\mathrm{T}$ statistics should be greater than 1.96 and $P$ value less than 0.05 for the acceptance of the underlying hypothesis (Ayele \& Birhanie, 2018; Suleman, Ali, Nusraningrum, \& Ali, 2019).

The study found a significant positive influence of Accessibility on Intention to Use the Mobile Renewal Service. The positive path coefficient of $0.114(P<$ 0.001) suggests that Accessibility accounts for about 11.4 percent of subscriber Intention to Use the Mobile Renewal Service, supporting $H_{3}$. The findings imply that the Mobile Renewal Service platform Accessibility counts very much in NHIS subscribers' Intention to Use the Mobile Renewal Service.

One of the main TAM variables, Perceived Ease of Use relates directly significantly with Intention to Use the Mobile Renewal Service. Perceived Ease of Use has a significant positive influence of $0.256(P<0.001)$ path coefficient on Intention to Use, supporting $H_{4}$. Here, Perceived Ease of Use of the Mobile Renewal Service counts for about 25.6 percent Intention to Use. The result shows that the Mobile Renewal Service platform Perceived Ease of Use counts very much in NHIS subscribers' Intention to Use the Mobile Renewal Service.

Perceived Usefulness relates directly significantly with Intention to Use the Mobile Renewal Service. Perceived Usefulness has a significant positive influence of $0.223(P<0.001)$ path coefficient on Intention to Use, supporting $H_{5}$. Here, Perceived Usefulness of the Mobile Renewal Service counts for about 22.3 percent Intention to Use. The result shows that the Perceived Usefulness of the Mobile Renewal Service counts very much in NHIS subscribers' Intention to Use the Mobile Renewal Service.

Table 7 also reports a significant positive nexus between System Quality and Intention to Use. The path coefficient of $0.384(P<0.001)$ indicates that System Quality accounts for about 4.4 percent Intention to Use the Mobile

Table 7. The path coefficient for the structural model involving direct effects.

\begin{tabular}{ccccc}
\hline Hypothesis & Paths & Coefficients & T Values & Results \\
\hline$H_{3}$ & Accessibility $\rightarrow$ Intention to Use & $0.114^{\star * *}$ & 2.856 & Supported \\
$H_{4}$ & Perceived Ease of Use $\rightarrow$ Intention to Use & $0.256^{\star * *}$ & 3.811 & Supported \\
$H_{5}$ & Perceived Usefulness $\rightarrow$ Intention to Use & $0.223^{\star * *}$ & 3.376 & Supported \\
$H_{1}$ & System Quality $\rightarrow$ Intention to Use & $0.384^{\star * *}$ & 6.772 & Supported \\
& Transaction Cost $\rightarrow$ Intention to Use & -0.028 & 1.024 & $\begin{array}{c}\text { Not } \\
\text { supported }\end{array}$ \\
\hline
\end{tabular}

Note: Significance levels: $\mathrm{n} / \mathrm{s}=$ not significant; ${ }^{\star} 0.05,{ }^{\star *} 0.01,{ }^{\star * *} 0.001$. Source: Author's construct. 
Renewal Service, supporting $H_{1}$. The findings imply that the System Quality drive from the Mobile Renewal Service counts very much in subscriber Intention to Use.

Meanwhile, the study discovered an insignificant inverse association between Transaction Cost and Intention to Use. Transaction Cost exerts a negative path coefficient of $-0.028(P>0.05)$ on Intention to Use such that the former accounts for about 2.8 percent less Intention to Use, supporting $H_{2}$. The Transaction Cost of the Mobile Renewal Service has a negative impact on subscriber Intention to Use, notwithstanding its insignificance.

Predictive Relevance of the Models $Q^{2}$

This section reports the PLS model's prediction accuracy measured by $Q^{2}$. The $Q$ is a mix of out-of-sample prediction and in-sample explanatory power (Shmueli et al., 2016; Sarstedt et al., 2017a). Using these estimations as input, the blindfolding procedure estimates the data points that were excluded for all variables. As a general rule, $Q^{2}$ values larger than $0.00,0.25$, and 0.50 , respectively, show the PLS-path model's small, medium, and large predictive relevance (Sarstedt et al., 2017a). According to the findings in Table 8, the study respectively reports 0.615 (Strong Predictive Relevance) and 0.569 (Strong Predictive Relevance) $Q^{2}$ values for Intention to Use and Perceived Usefulness.

\section{Goodness of Fit}

Running a robustness test to validate the results' stability constitutes the final stage in interpreting PLS-SEM findings. The importance of the robustness check is determined by the research context, such as the analysis' goal and data availability (Ayele \& Birhanie, 2018). The study used the standardized root mean square residual (SRMR), which measures the approximate fit of a research model by determining the difference between the observed correlation matrix and the model inferred correlation matrix. When the SRMR is less than 0.08 , the model is very well (Hu \& Bentler, 1998). The SRMR value observed in this study is less than the threshold value (see Table 9).

Table 8. Predictive accuracy of the structural model.

\begin{tabular}{ccccc}
\hline Constructs & SSO & SSE & $\begin{array}{c}\text { Q2 } \\
(=1-\text { SSE/SSO })\end{array}$ & $\begin{array}{c}\text { Predictive } \\
\text { Relevance }\end{array}$ \\
\hline Accessibility & 810 & 810 & & \\
Intention to Use & 1215 & 468.138 & 0.615 & $\begin{array}{c}\text { Strong Predictive } \\
\text { Relevance }\end{array}$ \\
Perceived Ease of Use & 1215 & 1215 & & $\begin{array}{c}\text { Selevance } \\
\text { Perceived Usefulness }\end{array}$ \\
System Quality & 1215 & 524.229 & 0.569 & \\
Transactional Cost & 1215 & 1215 & & \\
\hline
\end{tabular}

Source: Author's construct. 
Table 9. Standardized root mean square residual outcome.

\begin{tabular}{lcccc}
\hline & Original Sample (O) & Sample Mean $(\mathrm{M})$ & $95 \%$ & $99 \%$ \\
\hline Saturated Model & 0.051 & 0.034 & 0.061 & 0.094 \\
Estimated Model & 0.057 & 0.037 & 0.057 & 0.094
\end{tabular}

Source: Author's construct.

\section{Discussing Factors Influencing Subscribers' Use and Adoption of the Mobile Renewal Service}

This study examines the effect of System Quality, Transaction Cost, Accessibility, Perceived Ease of Use, and Perceived Usefulness on subscribers' Intention to Use the service.

First and foremost, the study found a significant positive influence of Accessibility on Intention to Use the Mobile Renewal Service. The findings imply that Mobile Renewal Service Platform Accessibility counts very much in NHIS subscribers' Intention to Use the Mobile Renewal Service. The relevance of Accessibility in determining individuals' Intention to Use a system cannot be overlooked in the extended TAM. Accessibility has been argued in the extent of literature to be a sound predictor of new system usage (Culnan, 1985; Rice \& Shook, 1988; Kerr \& Hiltz, 1982). Given the explanation that all else being equal, the easier the system is to interact with, the less effort will be needed to use it (Davis, 1989), it is reasonable to suggest that physical and information Accessibility of the mobile renewal service can have a significant impact on users' Intention to Use. The findings from several other studies (Zhou, Bao, Watzlaf, \& Parmanto, 2019) affirm the importance of Accessibility in predicting potential users' intention to accept and use a new system.

Also, the results indicate that one of the main TAM variables, Perceived Ease of Use relates directly significantly with Intention to Use the Mobile Renewal Service. The result shows that the Mobile Renewal Service Platform Perceived Ease of Use counts very much in NHIS subscribers' Intention to Use the Mobile Renewal Service. Perceived Ease of Use is one of the two constructs adopted from the TAM (Davis, Bagozzi, \& Warshaw, 1989) in predicting Intention to Use the Mobile Renewal Service among NHIS subscribers. IS can be accepted by users who want to utilize them, and the perceived usefulness and ease of use of those systems can help forecast this intention, according to the advocates of the TAM. The significant positive effect of Perceived Ease of Use on subscriber Intention to Use the Mobile Renewal Service is backed by several attestations in the extant mobile health literature (Abdekhoda, Ahmadi, Dehnad, Noruzi, \& Gohari, 2016; Basak, Gumussoy, \& Calisir, 2015; Holden, Asan, Wozniak, Flynn, \& Scanlon, 2016).

Accordingly, Perceived Usefulness relates directly significantly with Intention to Use the Mobile Renewal Service. The result shows that the Perceived Usefulness of the Mobile Renewal Service counts very much in NHIS subscribers' In- 
tention to Use the Mobile Renewal Service. The findings corroborate the prediction in the TAM which posits both Perceived Ease of Use and Perceived Usefulness as the driver of Intention to Use (Basak et al., 2015; Holden et al., 2016; Landry, Griffeth, \& Hartman, 2006; Maqableh, Masa'deh, \& Mohammed, 2015). According to the Theory of Reasoned Action (TRA), users' beliefs influence their attitude, which in turn influences behavioral intention (Ajzen \& Fishbein, 1980; Fishbein \& Ajzen, 1975). Both perceived usefulness and perceived ease of use are beliefs. Thus, they will affect the user's intentions.

The preceding empirical dynamics reported corroborating the outcome of the mediation analysis in response to how the effect of Perceived Ease of Use on subscriber Intention to Use the Mobile Renewal Service is mediated by Perceived Usefulness. According to the findings from this test, it was revealed that Perceived Usefulness significantly mediates the relationship between Perceived Ease of Use and Intention to Use. The finding suggests that the mediation role of Perceived Usefulness accounts for a substantial influence of Perceived Ease of Use on Intention to Use the Mobile Renewal Service, an effect comparatively lower than the direct impact. The mediation effect of Perceived Usefulness in the underlying nexus corroborates the finding in Al-sharafi, Arshah, Herzallah, and Alajmi (2017) which also used Perceived Trust to mediate the nexus between Perceived Usefulness and Intention to Use.

The study also reports a significant positive nexus between System Quality and Intention to Use suggesting that the quality drive from the Mobile Renewal Service counts very much in subscriber Intention to Use. The establishment of a significant positive effect of System Quality on Intention to Use gets theoretical backing from the UTAUT framework (Venkatesh \& Davis, 2000). According to Chang et al. (2011), the success of an information system is determined by the users' satisfaction with the system's overall quality. It was expected that the study will show that System Quality will have some effect on subscriber Intention to Use the Mobile Renewal Service. The confirmation of the hypothesis is consistent with predictions in the extant literature (Aljedaani, Ahmad, Zahedi, \& Babar, 2020).

Meanwhile, the study discovered an insignificant inverse association between Transaction Cost and Intention to Use. The Transaction Cost of the Mobile Renewal Service has a negative impact on subscriber Intention to Use, notwithstanding its insignificance. Transaction cost is an essential factor for users when considering whether to use a new system or not. For instance, the extant literature suggests that if consumers perceive the service's transaction cost as acceptable, they are likely to adopt it and then use it (Cline \& Luiz, 2013; Peng, Kanthawala, Yuan, \& Hussain, 2016; Zhou et al., 2019). According to Mathieson et al. 1991, economic motivations and outcomes are most often the focus of IS acceptance studies as found under the current scenario.

Interestingly, the study also found an insignificant positive influence of Trust on Intention to Use. 


\section{Conclusion}

The study made the following revelations about the determinants of subscriber intention to use the mobile renewal service:

1) A significant positive influence of accessibility on intention to use the mobile renewal service.

2) Perceived ease of use relates directly significantly with intention to use the mobile renewal service.

3) A significant positive influence of perceived ease of use on perceived usefulness.

4) Perceived usefulness relates directly significantly with intention to use the mobile renewal service.

5) Perceived usefulness significantly mediates the relationship between perceived ease of use and intention to use.

6) A significant positive nexus between system quality and intention to use.

7) An insignificant inverse association between transaction cost and intention to use.

Concerning the degree of subscriber intention to use the mobile renewal service, the current study made several discoveries. As part of the assessment, the study delved into the number of years subscribing to the NHIS and access to healthcare delivery under the scheme. The results suggest most of the sampled participants have had a good experience with regards to the usage of the NHIS and hence, the views and opinions expressed by them would better serve the course of this current investigation. The results show that majority of the sampled participants have access to healthcare delivery under the NHIS. The results also suggest that subscribers hold the view that the quality of healthcare delivery under the NHIS has been moderate and appreciable in the sampled districts within the northern region of Ghana. The analysis also clearly shows that majority of the NHIS subscribers are aware of the mobile renewal service in the sampled study area. The current further found that majority of the NHIS subscriber has ever used the mobile renewal service before in the sampled study area supporting the greater variance explained by the factors accounting for subscriber intention to use. According to the findings, the vast majority of subscribers believe that the overall quality of the mobile renewal service for accessing healthcare services in the sampled research locations has been outstanding. Consistent with the foregoing, the findings also show that the majority of the subscribers overwhelmingly endorsed the continuity of the mobile renewal service with an insignificant number of them advocating for its suspension.

The study established if factors such as system quality, transaction cost, accessibility, perceived ease of use, and perceived usefulness, facilitate or impede subscriber intention to use the mobile renewal service under the NHIS in the north of Ghana. Accordingly, the following conclusions can be inferred from the analysis:

1) It can be established that accessibility facilitates subscriber intention to use 
the mobile renewal service.

2) It can be concluded that perceived ease of use enables subscriber intention to use the mobile renewal service.

3) The study also concludes that perceived ease of use is capable of influencing perceived usefulness positively.

4) It can also be inferred that perceived usefulness increases subscriber intention to use the mobile renewal service.

5) Another interesting inference is that perceived usefulness influences the relationship between perceived ease of use and intention to use.

6) It can be maintained that system quality facilitates subscriber intention to use the mobile renewal service.

7) It can be established that transaction cost impedes subscriber intention to use the mobile renewal service.

\section{Recommendations}

\section{To Policymakers:}

1) The discovery of Accessibility, and System Quality, as facilitators of subscriber Intention to Use the Mobile Renewal Service provides a clue for system sustainable policy decision making.

2) The establishment of the TAM constructs (Perceived Ease of Use and Perceived Usefulness) in the subscriber Intention to Use dynamics also presents a solid platform for both policy and theoretical implications.

3) The insignificant negative effect of Transaction Cost in explaining subscriber Intention to Use the Mobile Renewal Service also makes room for continuation of current services charge without alterations.

4) The high rate of subscriber awareness of the Mobile Renewal Service but relatively low patronage suggests the need for further considerations as reported in this study. Policymakers should pay attention to System Quality, Accessibility, Perceived Ease of Use, and Perceived Usefulness.

\section{To the Subscribers:}

1) The insignificant the negative effect of Transaction Cost on Intention to Use suggests that the Mobile Renewal Service is affordable, hence, NHIS subscribers can employ it in renewing their subscriptions.

2) The appreciable quality of the Mobile Renewal Service reported in the current study should serve as a clue for general subscriber acceptance.

3) The three main gains discovered also present another justification for subscribers to accept and use the Mobile Renewal Service.

\section{To the Research Community:}

1) The methodology used in this study can be adopted in other territories while keeping in mind its drawbacks.

2) Qualitative means can be employed to consider service providers' opinions on implementation challenges.

3) Demographic variables can be used to moderate what factors facilitate or 
impedes subscriber intention to use.

\section{Conflicts of Interest}

The author declares no conflicts of interest regarding the publication of this paper.

\section{References}

Abdekhoda, M., Ahmadi, M., Dehnad, A., Noruzi, A., \& Gohari, M. (2016). Applying Electronic Medical Records in Health Care: Physicians' Perspective. Applied Clinical Informatics, 7, 341-354. https://doi.org/10.4338/ACI-2015-11-RA-0165

Afarikumah, E. (2014). Electronic Health in Ghana: Current Status and Prospects. Online Journal of Public Health Informatics, 5, 230. https://doi.org/10.5210/ojphi.v5i3.4943

Ajzen, I., \& Fishbein, M. (1980). Understanding Attitudes and Predicting Social Behavior. Prentice-Hall.

Aljedaani, B., Ahmad, A., Zahedi, M., \& Ali Babar, M. (2020). Security Awareness of End-Users of Mobile Health Applications: An Empirical Study. In 17th EAI International Conference on Mobile and Ubiquitous Systems: Computing, Networking and Services (pp. 125-136). Association of Computing Machinery (ACM) Digital Library. https://doi.org/10.1145/3448891.3448952

Al-Sharafi, M. A., Abdullah Arshah, R., Herzallah, F., \& Alajmi, Q. (2017). The Effect of Perceived Ease of Use and Usefulness on Customers Intention to Use Online Banking Services: The Mediating Role of Perceived Trust. International Journal of Innovative Computing, 7, 9-14.

Ayele, A., \& Birhanie, W. (2018). Acceptance and Use of e-Learning Systems: The Case of Teachers in Technology Institutes of Ethiopian Universities. Applied Informatics, 5, 1-11. https://doi.org/10.1186/s40535-018-0048-7

Barclay, D., Thompson, R., \& Higgins, C. (1995). The Partial Least Squares (PLS) Approach to Causal Modeling: Personal Computer Use as an Illustration. Technology Studies, 2, 285-309.

Barroso, C., Cepeda-Carrion, G., \& Roldán, J. (2010). Applying Maximum Likelihood and PLS on Different Sample Sizes: Studies on SERVQUAL Model and Employee Behavior Model. In Handbook of Partial Least Squares (pp. 427-447). Springer.

https://doi.org/10.1007/978-3-540-32827-8 20

Basak, E., Gummussoy, C. A., \& Calisir, F. (2015). Examining the Factors Affecting PDA Acceptance among Physicians: An Extended Technology Acceptance Model. Journal Healthcare Engineering, 6, Article ID: 582071. https://doi.org/10.1260/2040-2295.6.3.399

Bhattacherjee, A. (2001). Understanding Information Systems Continuance: An Expectation-Confirmation Model. MIS Quarterly, 25, 351-370. https://doi.org/10.2307/3250921

Chang, L. H., Chen, P., Lien, M. T., Ho, T. H., Lin, C. M., Pan, Y. T., Wei, S. Y., \& Hsu, J. C. (2011). Differential Adhesion and Actomyosin Cable Collaborate to Drive Echinoid-Mediated Cell Sorting. Development, 135, 3808-3812.

https://doi.org/10.1242/dev.062257

Chin, W. W. (1998). The Partial Least Squares Approach for Structural Equation Modeling. In G. A. Marcoulides (Ed.), Modern Methods for Business Research (pp. 295-336). Lawrence Erlbaum Associates. 
Chin, W., \& Marcoulides, G. (1998). The Partial Least Squares Approach to Structural Equation Modeling. Modern Methods for Business Research, 2, 295-336.

Cline, G., \& Luiz, J. (2013). Information Technology Systems in Public Sector Health Facilities in Developing Countries: The Case of South Africa. BMC Medical Informatics and Decision Making, 13, Article No. 13. https://doi.org/10.1186/1472-6947-13-13

Culnan, M. J. (1985). The Dimensions of Perceived Accessibility to Information: Implications for the Delivery of Information Systems and Services. Journal of the American Society for Information Science, 36, 302-308. https://doi.org/10.1002/asi.4630360504

Davis, F. D. (1989). Perceived Usefulness, Perceived Ease of Use and User Acceptance of Information Technology. MIS Quarterly, 13, 319-340. https://doi.org/10.2307/249008

Davis, F. D., \& Cosenza, R. M. (1993). Business Research for Decision Making. Wadsworth.

Davis, F., Bagozzi, R., \& Warshaw, P. (1989). User Acceptance of Computer Technology: A Comparison of Two Theoretical Models. Management Science, 35, 982-1003. https://doi.org/10.1287/mnsc.35.8.982

Dillon, A., \& Morris, M. (1996). User Acceptance of Information Technology: Theories and Models. Annual Review of Information Science and Technology, 31, 3-32.

Fishbein, M., \& Ajzen, I. (1975). Belief, Attitude, Intention, and Behaviour: An Introduction to Theory and Research. Addison-Wesley.

Fornell, C., \& Larcker, D. F. (1981). Evaluating Structural Equation Models with Unobservable Variables and Measurement Error. Journal of Marketing Research, 18, 39-50. https://doi.org/10.1177/002224378101800104

Geroge, B. (2003). Authentic Leadership: Rediscovering the Secrets to Creating Lasting Value. Addison-Wesley.

Ghana Statistical Service (GSS), Ghana Health Service (GHS), \& ICF International (2015). Ghana Demographic and Health Survey 2014. GSS, GHS, and ICF International. http://dhsprogram.com/pubs/pdf/FR307/FR307.pdf

Götz, O., Liehr-Gobbers, K., \& Krafft, M. (2010). Evaluation of Structural Equation Models Using the Partial Least Squares (PLS) Approach. https://doi.org/10.1007/978-3-540-32827-8 30

Hair Jr., J. F., Black, W. C., Babin, B. J., Anderson, R. E., \& Tatham, R. (2006). Multivariate Data Analysis. Pearson International Edition.

Hair, J. F., Hult, G. T. M., Ringle, C. M. et al. (2017). Mirror, Mirror on the Wall: A Comparative Evaluation of Composite-Based Structural Equation Modeling Methods. Journal of the Academy of Marketing Science, 45, 616-632. https://doi.org/10.1007/s11747-017-0517-x

Hair, J. F., Risher, J. J., Sarstedt, M., \& Ringle, C. M. (2019). When to Use and How to Report the Results of PLS-SEM. European Business Review, 31, 2-24. https://doi.org/10.1108/EBR-11-2018-0203

Henseler, J., Ringle, C. M., \& Sinkovics, R. R. (2009). The Use of Partial Least Squares Path Modelling in International Marketing. In R. R. Sinkovics, \& P. N. Ghauri (Eds.), New Challenges to International Marketing (Advances in International Marketing) (Vol. 20, pp. 277-319). Emerald Group Publishing Limited. https://doi.org/10.1108/S1474-7979(2009)0000020014

Holden, R., Asan, O., Wozniak, E., Flynn, K., \& Scanlon, M. (2016). Nurses’ Perceptions, Acceptance, and Use of a Novel In-Room Pediatric ICU Technology: Testing an Expanded Technology Acceptance Model. BMC Medical Informatics and Decision Making, 16, Article No. 145. https://doi.org/10.1186/s12911-016-0388-y 
Hu, L., \& Bentler, P. M. (1998). Fit Indices in Covariance Structure Modeling: Sensitivity to Underparamerterized Model Misspecification. Psychological Methods, 3, 424-453. https://doi.org/10.1037/1082-989X.3.4.424

Hulland, J. (1999). Use of Partial Least Squares (PLS) in Strategic Management Research: A Review of Four Recent Studies. Strategic Management Journal, 20, 195-204. https://doi.org/10.1002/(SICI)1097-0266(199902)20:2<195::AID-SMJ13>3.0.CO;2-7

Ifinedo, P. (2015). Effects of Organisational Citizenship Behaviour and Social Cognitive Factors on Employees Non-Malicious Counterproductive Computer Security Behaviours: An Empirical Analysis. In CONF-IRM 2015 Proceedings (p. 36). Association for Information Systems AIS Electronic Library (AISeL). https://aisel.aisnet.org/confirm2015/36

Kerr, E. B., \& Hiltz, S. R. (1982). Computer-Mediated Communication System: Status and Evaluation. Academic Press.

Kim, S., Lee, K. H., Hwang, H., \& Yoo, S. (2016). Analysis of the Factors Influencing Healthcare Professionals' Adoption of Mobile Electronic Medical Record (EMR) Using the Unified Theory of Acceptance and Use of Technology (UTUAT) in a Tertiary Hospital. BMC Medical Informatics and Decision Making, 16, Article No. 12. https://doi.org/10.1186/s12911-016-0249-8

Kumar, R. (2011). Research Methodology: A Step-by-Step Guide for Beginners (3rd ed.). Sage.

Landry, B., Griffeth, R., \& Hartman, S. (2006). Measuring Student Perceptions of Blackboard Using the Technology Acceptance Model. Decision Sciences Journal of Innovative Education, 4, 87-99. https://doi.org/10.1111/j.1540-4609.2006.00103.x

Lin, H. F. (2007). Knowledge Sharing and Firm Innovation Capability: An Empirical Study. International Journal of Manpower, 28, 315-332. https://doi.org/10.1108/01437720710755272

Luarn, P., \& Lin, H.-H. (2005). Toward an Understanding of the Behavioral Intention to Use Mobile Banking. Computers in Human Behavior, 21, 873-891. https://doi.org/10.1016/j.chb.2004.03.003

Luke, I., Omwansa, T., \& Mwololo, T. (2012). Application of Technology Acceptance Model (TAM) in M-Banking Adoption in Kenya. International Journal of Computing and ICT Research, 6, 31-43.

Maqableh, M., Masa'deh, R., \& Bany, M. A. (2015). The Acceptance and Use of Computer Based Assessment in Higher Education. Journal of Software Engineering and Applications, 8, 557-574. https://doi.org/10.4236/jsea.2015.810053

Mathieson, K. (1991). Predicting User Intentions: Comparing the Technology Acceptance Model with the Theory of Planned Behavior. Information Systems Research, 2, 173-191. https://doi.org/10.1287/isre.2.3.173

Mohammed-Issa, R. J. (2013). Applying the Technology Acceptance Model to the Introduction of Mobile Voting. International Journal of Mobile Learning and Organisation, 7, 29-47. https://doi.org/10.1504/IJMLO.2013.051572

Peng, W., Kanthawala, S. et al. (2016). A Qualitative Study of User Perceptions of Mobile Health Apps. BMC Public Health, 16, Article No. 1158. https://doi.org/10.1186/s12889-016-3808-0

Rice, R. E., \& Shook, D. E. (1988). Access to Usage of and Outcomes from an Electronic Messaging System. ACM Transactions on Information Systems, 6, 255-276. https://doi.org/10.1145/45945.214325

Roldán, J., \& Sánchez-Franco, M. J. (2012). Variance-Based Structural Equation Model- 
ing: Guidelines for Using Partial Least Squares in Information Systems Research. In M. Mora, O. Gelman, A. Steenkamp, \& M. Raisinghani (Eds.), Research Methodologies, Innovations and Philosophies in Software Systems Engineering and Information Systems (pp. 193-221). IGI Global. https://doi.org/10.4018/978-1-4666-0179-6.ch010

Safi, S., Thiessen, T., \& Schmailzl, K. J. (2018). Acceptance and Resistance of New Digital Technologies in Medicine: Qualitative Study. JMIR Research Protocols, 7, e11072. https://doi.org/10.2196/11072

Sakala, L., \& Phiri, J. (2019). Factors Affecting Adoption and Use of Mobile Banking Services in Zambia Based on TAM Model. Open Journal of Business and Management, 7, 1380-1394. https://doi.org/10.4236/ojbm.2019.73095

Sarstedt, M., Ringle, C. M., \& Hair, J. F. (2017). Partial Least Squares Structural Equation Modeling. In C. Homburg, M. Klarmann, \& A. Vomberg (Eds.), Handbook of Market Research (pp. 1-40). Springer. https://doi.org/10.1007/978-3-319-05542-8 15-1

Sarstedt, M., Ringle, C., \& Hair, J. (2017). Partial Least Squares Structural Equation Modeling. In Handbook of Market Research (pp. 1-47). Springer. https://doi.org/10.1007/978-3-319-05542-8 15-1

Schwarz, N. (2007). Evaluation in Context.

Shmueli, G., Ray, S., Velasquez-Estrada, J., \& Chatla, S. (2016). The Elephant in the Room: Predictive Performance of PLS Models. Journal of Business Research, 69, 4552-4564. https://doi.org/10.1016/j.jbusres.2016.03.049

Suleman, D., Ali, H., Nusraningrum, D., \& Ali, M. M. (2019). Perceived Ease of Use, Trust and Risk toward Attitude and Intention in Shopping for Online Fashion Products In Indonesia. Archives of Business Research, 7, 240-253.

Tenehaus, M., Vinzi, V. E., Chatelin, Y. M., \& Lauro, C. (2005). PLS Path Modeling. Computational Statistics \& Data Analysis, 48, 159-205. https://doi.org/10.1016/j.csda.2004.03.005

Urbach, N., \& Ahlemann, F. (2010). Structural Equation Modeling in Information Systems Research Using Partial Least Squares. Journal of Information Technology Theory and Application, 11, Article 2.

Venkatesh, V., \& Davis, F. (2000). A Theoretical Extension of the Technology Acceptance Model: Four Longitudinal Field Studies. Management Science, 46, 186-204. https://doi.org/10.1287/mnsc.46.2.186.11926

Wojciechowski, R., \& Cellar, W. (2013). Evaluation of Learners' Attitude toward Learning in ARIES Augmented Reality Environments. Computers \& Education, 68, 570-585. https://doi.org/10.1016/j.compedu.2013.02.014

Zhou, L., Bao, J., Watzlaf, V., \& Parmanto, B. (2019). Barriers to and Facilitators of the Use of Mobile Health Apps from a Security Perspective: Mixed-Methods Study. JMIR mHealth and uHealth, 7, e11223. https://mhealth.jmir.org/2019/4/e11223 https://doi.org/10.2196/11223 